\title{
Article
}

\section{Oral Medicine for undergraduate dental students in the United Kingdom and Ireland-A curriculum}

Mighell, A. J., Freeman, C., Atkin, P. A., Bennett, J. H., Buchanan, J. A. G., Carrozzo, M., Crighton, A. J., Escudier, M. P., Gibson, J., Healy, C. M., Hegarty, A. M., Kerr, Julian Simon, McCreary, C. E., Pemberton, M. N., Rajlawat, B., Richards, A., Staines, K., Theaker, E. D. and Willis, A.

Available at http://clok.uclan.ac.uk/23145/

Mighell, A. J., Freeman, C., Atkin, P. A., Bennett, J. H., Buchanan, J. A. G., Carrozzo, M., Crighton, A. J., Escudier, M. P., Gibson, J. et al (2018) Oral Medicine for undergraduate dental students in the United Kingdom and Ireland-A curriculum. European Journal of Dental Education, 22 (4). e661e668. ISSN 1396-5883

It is advisable to refer to the publisher's version if you intend to cite from the work. http://dx.doi.org/10.1111/eje.12366

For more information about UCLan's research in this area go to http://www.uclan.ac.uk/researchgroups/ and search for <name of research Group>.

For information about Research generally at UCLan please go to http://www.uclan.ac.uk/research/

All outputs in CLoK are protected by Intellectual Property Rights law, including Copyright law. Copyright, IPR and Moral Rights for the works on this site are retained by the individual authors and/or other copyright owners. Terms and conditions for use of this material are defined in the policies page. 


\section{Oral Medicine for Undergraduate Dental Students in the United}

\section{Kingdom and Ireland - A Curriculum}

A. J. Mighell ${ }^{1}$, C. Freeman', P. A. Atkin ${ }^{3}$, J.H.Bennett ${ }^{4}$, J.A.G. Buchanan ${ }^{5}$, M. Carrozzo ${ }^{6}$, A. J. Crighton ${ }^{7}$, M. P. Escudier $^{8}$, J. Gibson ${ }^{9}$, C. M. Healy ${ }^{10}$, A. M. Hegarty ${ }^{2}$, J. S. Kerr ${ }^{11}$, C. E. McCreary ${ }^{12}$, M. N. Pemberton ${ }^{13}$, B. Rajlawat $^{14}$, A. Richards ${ }^{15}$, K. Staines ${ }^{16}$, E. D. Theaker ${ }^{17}$ and Willis A. ${ }^{18}$.

${ }^{1}$ The University of Leeds, England.

${ }^{2}$ The University of Sheffield, England.

${ }^{3}$ Cardiff University, Wales.

${ }^{4}$ Plymouth University, England.

${ }^{5}$ The University of London (Queen Mary), England.

${ }^{6}$ The University of Newcastle, England.

${ }^{7}$ The University of Aberdeen, Scotland.

${ }^{8}$ The University of London (Kings College), England.

${ }^{9}$ The University of Glasgow Scotland.

${ }^{10}$ The University of Dublin Ireland.

${ }^{11}$ University of Central Lancashire, England.

${ }^{12}$ The University of Cork, Ireland.

${ }^{13}$ The University of Manchester, England.

${ }^{14}$ The University of Liverpool, England.

${ }^{15}$ The University of Birmingham, England.

${ }^{16}$ The University of Bristol, England.

${ }^{17}$ The University of Dundee, Scotland.

${ }^{18}$ Queen's University Belfast, Northern Ireland.

Key words: undergraduate, curriculum, oral medicine, outcomes.

\section{Corresponding author:}

Dr Alan J. Mighell

Department of Oral Medicine

School of Dentistry

The University of Leeds

Clarendon Way

Leeds

LS2 9LU

Telephone: +44 (0) 1133436121 
e-mail: a.j.mighell@leeds.ac.uk

Running title: oral medicine undergraduate curriculum 


\begin{abstract}
Introduction: Oral Medicine focuses on care for patients with chronic, recurrent and medically-related disorders of the oro-facial region that are distinct from diseases of the periodontal and tooth tissues, with an emphasis on non-surgical management. At present there are no shared outcomes for Oral Medicine to define the standards to be achieved before new graduates become registered dentists engaged with ongoing professional development.
\end{abstract}

Curriculum: We present a consensus undergraduate curriculum in Oral Medicine agreed by representatives from 18 Dental Schools in the United Kingdom and Republic of Ireland. The scope of Oral Medicine practice includes conditions involving the oral mucosa, salivary glands, neurological system or musculoskeletal tissues that are not directly attributable to dental (tooth and periodontium) pathology. Account is taken of the priorities for practice and learning opportunities needed to support development of relevance to independent clinical practice. The outcomes triangulate with the requirements set out by the respective regulatory bodies in the UK and Republic of Ireland prior to first registration and are consistent with the framework for European undergraduate dental education and greater harmonisation of dental education.

Conclusions: This curriculum will act as a foundation for an increasingly shared approach between centres with respect to the outcomes to be achieved in Oral Medicine. The curriculum may also be of interest to others, such as those responsible for the training of dental hygienists and dental therapists. It provides a platform for future collective developments with the overarching goal of raising the quality of patient care. 


\section{Introduction}

More than $80 \%$ of registered dentists in the UK and Republic of Ireland (Rol) practice in primary care with a focus on the delivery of general dental healthcare to adults and children. Higher Educational Institutions (HEls) preparing the dental team for first registration are required to meet standards set by the regulatory bodies responsible for patient protection $(1,2)$. There is a need not only for uniform standards within nation states but also greater harmonisation between them, reflecting workforce movement. The framework for European undergraduate dental education reflects the principles of the Bologna Process and harmonisation of higher education in the 48 countries that form the European Higher Education Area (EHEA) (3).

Outcomes at undergraduate level need to relate to an individuals ongoing professional and career development. Dental Foundation Training in the UK is a structured one year transition period after first registration with associated learning outcomes (4). In the Rol dentists currently proceed to independent practice immediately upon graduation. Irrespective of any career structures there is the need for selfdirected educational engagement to ensure professional currency and development to meet patient needs.

In early career stage outcome-based documents the emphasis is on knowledge, skills, attitudes and behaviours across the breadth of practice in dentistry. Clinical discipline specific-detail is limited, which in part is likely to reflect the broad nature of early career clinical practice. The 2016 UK Dental Core Training (DCT) Curriculum does make clear distinctions between clinical disciplines, for example between Oral Medicine and Oral Surgery (5). However, only a small proportion of dental graduates will work in DCT posts. This situation highlights the need for clinical discipline specific outcome-based undergraduate curricula that triangulate with, and add value to, the outcomes required by the regulatory bodies for new graduates. The term 'curriculum' is used in its broadest sense to mean more than just the syllabus or course content but also the fundamental interlinked components of teaching and learning strategies, 
integrated assessment processes and ongoing evaluation underpinning delivery (6). For many graduates discipline specific curricula will form the basis for self-driven continuing professional development. Published curricula for specific areas of undergraduate dental education of direct relevance to development in Oral Medicine (7-10) along with other curricula, competency or consensus statements inform the 2017 ADEE update (3). Currently there is no collectively agreed undergraduate curriculum for Oral Medicine with clear outcomes, although brief comment on this area of practice (11) is included in the 2017 framework for European undergraduate dental education (3).

The British Society for Oral Medicine [www.bsom.org.uk], whose membership is primarily drawn from the United Kingdom and Rol, defines Oral Medicine as: "The specialty of dentistry concerned with the oral health care of patients with chronic, recurrent and medically related disorders of the oral and maxillofacial region, and with their diagnosis and non-surgical management". The emphasis on 'nonsurgical' management is a key distinction from the surgical specialties.

The scope of Oral Medicine practice includes conditions not directly attributable to the most prevalent tooth pathologies such as dental caries or chronic adult periodontal disease. Some presentations will have a clear iatrogenic component reflecting the consequences of prescribed medication or other interventions. Presentations may reflect local disease or orofacial manifestations of more widespread pathology affecting other parts of the body. There can be a significant aetiological component of psychological distress or disturbance. Oral health always needs to be viewed in the context of general physical and mental health, which has been recognised in the Clinical Medical Sciences curriculum (10). The newly registered dentist needs to actively contribute to clinical care (including prevention and active management) as well as liaise with, and refer to, other healthcare professionals.

To address the Oral Medicine undergraduate educational need, representatives from 18 Dental Schools in the United Kingdom and Rol considered the programme content, learning opportunities and outcomes 
related to Oral Medicine clinical practice. We propose a curriculum for Oral Medicine to inform the education of those aspiring to be added to the Dental Register for the first time and to provide a basis for subsequent continuing professional development.

\section{Oral Medicine for Undergraduate Dental Students -A Curriculum}

The curriculum is presented in three inter-related areas: competency framework, learning opportunities and assessment. These should be delivered within contemporary best educational approaches.

\section{A. Competency Framework}

The expected learning outcomes to be achieved in Oral Medicine by completion as a dental student are described within a competency framework where Table 1 sets out relevant clinical presentations (with examples) and Table 2 defines key management decisions to consider for each condition (Tables $1 \& 2$ ). For undergraduate students in the UK and Rol the outcomes are concordant with those required by the UK General Dental Council and Dental Council of Ireland, respectively $(1,2)$.

\section{Scope of Oral Medicine Practice}

The scope of practice for Oral Medicine includes conditions affecting the oral soft tissues, salivary glands, neurological tissue, and facial musculoskeletal tissues. Accordingly, there is a need to recognise the overlap with other areas of healthcare practice, particularly with clinical medicine and surgery as well as histopathology and laboratory sciences (10). Understanding normal structure and function provides the reference points necessary for insight into abnormal states that present as clinical problems. This understanding should translate systematic evaluation of the orofacial and other tissues where indicated, to inform clinical decision-making. The spectrum of normality includes changes associated with ageing (infancy to old age) and other natural states such as pregnancy and breast-feeding, as well as those 
associated with ethnic origins. The examples given in Table 1 are illustrative of relevant conditions, but should not be considered to represent a defining list of conditions to the exclusion of others.

Oral mucosa has a limited repertoire of responses to disease and a very wide range of diagnoses can present as white, red or ulcerated lesions. True white patches that cannot be rubbed off represent epithelial hyperkeratosis. Red patches are a consequence of epithelial atrophy (or desquamation) and/or mucosal inflammation. Vesicles or bullae are more likely to persist when formed at the epithelial basement membrane compared to within epithelium and on breaking down lead to an ulcer. Ulceration or erosion reflect the complete or partial loss of surface epithelium, respectively.

Localised oral soft tissue swelling most typically represents focal pathological cellular overgrowth or retention of minor salivary gland secretions. Oedema involving the mucosa and submucosa with possible involvement of the associated skin is reflected in more generalised soft tissue swelling. Salivary gland disorders mostly involve the major and minor glands in a generalised way with abnormalities to salivary gland size or function. Disorders of salivary gland function need to be distinguished from perceived alterations of quantity or quality of saliva that have poorly defined neurological components.

Neurological disorders include conditions characterised by pain or other altered sensation (e.g. disturbed taste) and cranial nerve deficits.

Bone disorders include diagnoses characterised by altered bone quantity or quality that are often indicative of more widespread conditions. Musculoskeletal conditions include those affecting the function of the temporomandibular joint and associated soft tissues.

Priorities for Oral Medicine Practice 
The priorities for practice are of relevance to all the conditions that fall within the scope of practice (Table 2). These help inform decision-making including what can be managed within the practitioner's competence. There may be a need for liaison with other healthcare profressionals. When formal referral is indicated this should be effected within an appropriate timeframe and manner. This should include routes where cancer may be present (e.g. 'Two-Week Wait', 'fast-track' and similar processes) (12) and expedited referral for other situations where other 'high stakes' diagnoses are suspected. Effective communication with all involved and appropriate record-keeping are central to high quality care.

\section{B. Learning Opportunities}

The learning opportunities provided within the scope of Oral Medicine practice need to be inclusive and take account of different learning styles that allow individuals to reach common endpoints via different routes. The challenges of linking teaching outside the clinic to that involving clinical care are recognised across healthcare (13). Irrespective of the approaches used, all need to deliver the common goal of supporting development of adequate clinical-reasoning and decision-making skills at the point of becoming a registered dentist.

The knowledge base that underpins Oral Medicine practice is traditionally delivered by lectures or similar learning events with supporting materials within each $\mathrm{HEl}$ and these resources are widely available. At undergraduate level Oral Medicine knowledge can feel remote from clinical care reflecting cognitive overload and lack of relevant clinical experience. There is scope to rationalise and share knowledge resources between HEls and also to support students in preparation for exposure to Oral Medicine clinical practice.

Case-based discussion of prepared cases with images, investigation results and other information can provide excellent learning opportunties that facilitate exploration, reflection and development of clinical 
decision-making. Consideration should be given to inclusion of a range of conditions that reflect those most commonly encountered as well as less frequently encountered conditions with potentially serious consequences. Possible errors or limitations in decision-making should be highlighted to reflect not only the impact on the individual, but also the patients journey through the healthcare system. This provides the opportunity to explore referral best practice along with shared care and other ways of delivering healthcare while recognising that there are location-specific variations. Face-to-face small groupteaching is staff intensive, but prepares students for direct clinical contact. There is scope to utilise technology to provide flexibility of opportunties and support learning.

The fundamental importance of real patient contact to clinical learning was championed over 100 years ago by Sir William Osler and remains central to preparing the next generation of clinicians (14). Oral Medicine learning opportunities should include adequate clinical exposure to relevant patients with students actively contributing to care. Attachments in dedicated clinics led by specialists in Oral Medicine provide a focused experience across the scope of practice and should be expected by undergraduate students. Time in clinic supports student learning in placing other learning opportunities within the context of actual patient experiences. It also highlights issues fundamental to good referral practice and responsibilities of the practitioners involved in care. This includes those related to determination of which patients require specialist care (either in Oral Medicine or other specialties), which patients will benefit from shared care and those where care in primary care settings alone is appropriate within understanding of the patient journey through the healthcare system. Pressure on clinical teaching opportunities are a major risk to undergraduate development in Oral Medicine reflecting two broad themes. Firstly, there needs to be adequate clinical time in Oral Medicine allocated within the undergraduate programme to allow all students opportunities to develop as individual clinicians. This may require a shift from historic arrangments to ensure an appropriate balance between different clinical disciplines. Secondly, when students are in clinic the learning opportunties should not be eroded, for example by either clinical service pressures, cases inappropriate for undergraduate 
development, insufficient teaching staff or the development demands of others such as postgraduate students, DCTs or specialty trainees present in the same clinic.

Oral Medicine clinical learning opportunities will also be available in other settings such as outreach clinics where there are parallels with primary dental care practice. Associating these possibilities with student development in Oral Medicine warrants consideration within each programme with appropriate tutor support.

\section{Assessment}

Meaningful assessment underpins assurance of professional development and standards of safe and appropriate care prior to first registration (15). Assessment strategies vary between HEIs in the UK and the Rol, reflecting developments over time inside individual organisations within a framework of external quality assurance. Individual Dental Schools have differing assessments that include Oral Medicine content and how performance specifically in this clinical discipline contributes to student progression.

Assessment should involve sampling across the range of competencies presented and may be at different points in the undergraduate programme via different assessment methods to inform student progression. The assessments must ultimately contribute to the decision-making process about whether each student is ready to make the transition to being a registered dentist accountable for their own actions, errors and omissions within the paramount need to protect the public. Assessments should include elements of decision-making that reflect appropriate clinical practice and should not place an over-emphasis on knowledge. There is a role for workbased or similar assessments with input from peers and patients to promote student reflection. Assessment must also take account of the systems that a registrant will practice within including appropriate working with other healthcare professionals and use of referral. 


\section{Discussion}

This collectively agreed curriculum is the first for undergraduate Oral Medicine. It sets out clear outcomes to prepare new graduates to a common standard before entry to the workplace as independent healthcare professionals able to deliver safe and appropriate care in this clinical discipline. As with any clinical curriculum we anticipate that it will develop over time to better meet the needs of clinicians and patient care. The outcomes triangulate with the requirements set out by the respective regulatory bodies in the UK and Rol and are consistent with the framework for European undergraduate dental education (1-3). The curriculum is a consensus between 18 Dental Schools and Institutes in the UK and ROI that takes account of the Bologna Process and recognition of increasing workforce movement. It represents an important development for Oral Medicine, which at the early career stage does not have a distinctive profile internationally. By contrast, there is an increasing international appetite for standardisation of advanced training in Oral Medicine (16).

Patterns of healthcare needs are altering with changes to global disease patterns, population demographics (such as greater numbers of older people and increased migration), together with advances in healthcare that will prolong life for more people than ever before (17-22). An increased negative impact on oral health can be expected. An agility will be required by new graduates to accommodate variations and change within their Oral Medicine clinical practice that will be influenced by where they work in the world and changes over time. These trends indicate an increased prevalence of clinical problems that fall within the scope of Oral Medicine. The need to define the standards to be achieved in Oral Medicine prior to registration as an independent dental practitioner has never been greater.

The intention is also that the curriculum provides a foundation for newly registered dentists to develop professionally in Oral Medicine through their working careers. Failure to establish solid foundations to 
clinical practice at this early career stage will be difficult to rectify as the individuals professional career progresses. Professional development is driven by the individual after Foundation Traning and Dental School graduation in the UK and Rol, respectively. There aren't the structured training programmes that typify career progression in medicine.

The curriculum presented may be of benefit to other Dental Schools responsible for preparing future generations of dentists. It may act as a stimulus for debate and subsequent development with the overarching goal of improving the equity and quality of patient care within best use of resources. Although the curriculum presented is directed at the education of the undergraduate dental student there are aspects that are applicable to the training of other members of the dental team including dental hygienists and therapists (1). The curriculum may also be of use to the training of other healthcare professionals whose learning opportunities and outcomes are limited with respect to oral health and how this links to general health (17).

Four main groups of conditions have been included in Table 1 to help inform and direct student learning and professional development. The boundaries between the groups are not rigid and in some instances a patients problems can be multi-factorial. This point emphasizes the need for appropriate, supported clinical exposure to ensure that the pragmatic issues of patient care can be experienced by students.

The examples given in Table 1 are illustrative. Irrespective of the condition encountered the clinical decision-making and ongoing care will be influenced by the factors described in Table 2. Many oral symptoms and signs reflect a condition that primarily involves other parts of the body, or arise as a consequence of healthcare management. It is the expectation that the newly graduating dentist recognises these possibilities and advances patient care in a timely way. This includes initiation of care to improve the patients situation, even when a definitive diagnosis has not yet been made. For all conditions the dentist needs to recognise their own limits of competence with effective, appropriate 
referral to other healthcare professionals in selected instances. Understanding health service organisation and associated patient journeys are central to high standards of care. Oral Medicine Managed Clinical Networks (MCNs) remain in their infancy in the UK and the Rol (23). As MCNs develop the importance of a common, defined standard at graduation will be more apparent as new insight about referrer behaviour helps to refine educational strategy and referral guidelines.

Clear overlap exists between subject specific undergraduate curricula. There are shared issues between the curriculum presented and the curriculum for Clinical Medical Sciences (CMS) for undergraduate dental students in the UK and Rol that focuses on general health issues of relevance to oral healthcare planning and delivery (10). The two curricula should be considered together in delivering student education in Oral Medicine. The focus in Oral Surgery (8) is different with an emphasis on surgical management that is complimentary to the curriculum presented. Competence in relevant aspects of Oral Pathology $(7,11)$ and Oral Radiology $(9)$ are essential for appropriate, informed patient care in Oral Medicine. Current education arrangements in each $\mathrm{HEl}$ in part reflect historical arrangements between related specialties including Oral Medicine, Oral (\& Maxillofacial) Surgery, Oral (\& Maxillofacial) Pathology, Dental (\& Maxillofacial) Pathology and Clinical Medical Sciences (Human Disease; Medicine \& Surgery). An integrated approach to education is desirable. Each centre should take account of how complementary curricula are delivered to ensure educational experiences that will best inform safe clinical practice and provide a foundation for ongoing profressional development.

Undergraduate dental programmes are busy with pressures on clinical time. It is essential that students are prepared to make the most of the clinical time through prior preparation. Others have demonstrated that reorganisation of the educational opportunities can improve student satisfaction within the context of pressures on clinical time (24). Failure to allow sufficient quality clinical time for student development in Oral Medicine will be self-defeating and impact negatively on patient care and referral behaviour. 
Assessment drives student learning (25). The biggest challenge in delivering this curriculum is development of assessment that contributes effectively to the decision that a dental undergraduate is ready for registration and independent practice. The complexities and challenges associated with this decision for each HEl are multiple (26). Other areas of healthcare are addressing the issues in their own way. For example, the UK General Medical Council are working towards a UK-wide Medical Licensing Assessment (MLA) for medical school undergraduates with the aim of "a single, objective demonstration that those applying for registration with a licence to practise medicine in the UK can meet a common threshold for safe practice."(27).

Collaboration in assessment between HEls could enhance Oral Medicine curriculum delivery. In addition to standardizing the assessment, this initiative would act to provide feedback on local curriculum delivery and provide more powerful psychometric data about individual assessment items. Such an approach would be a fundamental change to current practices. Whilst there is scope for advances to be made in collaborative assessment of this curriculum, significant progress will probably only follow strategic policy decisions in nation states across all aspects of progression from undergraduate to independent practitioner.

\section{Conclusions}

A need has been identified for greater clarity on the standards to be achieved with respect to the scope of Oral Medicine practice prior to registration as an independent dental practitioner. A consensus curriculum agreed between 18 Dental Schools and Institutes in the United Kingdom and the Rol is presented that triangulates with the requirements of the Dental Councils for each country. This should act as a focus for increasing alignment towards common standards and act as a platform for further 
development with the overarching goal of raising the standards of equitable patient care delivered in appropriate settings. 


\section{References}

1. General Dental Council UK. Preparing for Practice. London: General Dental Council, 2015 (revised edition). https://www.gdc-uk.org/professionals/education

2. Dental Council of Ireland. Guidelines for Dental Education. Dublin: Dental Council of Ireland, 2005. http://www.dentalcouncil.ie/

3. Field JC, Cowpe JG, Walmsley AD. The Graduating European Dentist: A new undergraduate curriculum framework. Eur J Dent Educ 2017: 21 Suppl 1: 2-10.

4. Committee of Postgraduate Dental Deans and Directors. Dental Foundation Training Curriculum. COPDEND, 2015.

http://www.copdend.org/content.aspx?Group=foundation\&Page=foundation dental\%20foundation \%20curriculum

5. Committee of Postgraduate Dental Deans and Directors. Dental Core Training Curriculum. COPDEND, 2016.

6. Prideaux, D. ABC of learning and teaching in medicine. Curriculum design. Br Med J 2003: 326: 268270.

7. Odell EW, Farthing PM, High A, et al. British Society for Oral and Maxillofacial Pathology, UK: minimum curriculum in oral pathology. Eur J Dent Educ 2004: 8: 177-184.

8. Macluskey M, Durham J, Cowan G, et al. UK national curriculum for undergraduate oral surgery subgroup for teaching of the Association of British Academic Oral and Maxillofacial Surgeons. Eur J Dent Educ 2008: 12: 48-58.

9. IADMFR Education Standards Committee. Undergraduate dental education in dental and maxillofacial radiology. Dentomaxillofac Radiol 2007: 36: 443-450.

10. Mighell AJ, Atkin PA, Webster K et al. Clinical medical sciences for undergraduate dental students in the United Kingdom and Ireland - a curriculum. Eur J Dent Educ 2011: 14: 1-10. 
11. Kragelund C, Reibel J, Hadler-Olsen ES et al. Scandinavian Fellowship for Oral Pathology and Oral Medicine: statement on oral pathology and oral medicine in the European Dental Curriculum. J Oral Pathol Med. 2010: 39:800-801.

12. National Institute for Health and Care Excellence. Referral Guidelines for Suspected Cancer. National Institute for Health and Care Excellence. London: 2015. https://www.nice.org.uk/Guidance/CG27

13. Peters S, Clarebout G, Diemers A, Delvaux N, Verburgh A, Aertgeerts B, Roex A. Enhancing the connection between the classroom and the clinical workplace: A systematic review. Perspect Med Educ 2017: 6: 148-157.

14. Bell K, Boshuizen HP, Scherpbier A, Dornan T. When only the real thing will do: junior medical students' learning from real patients. Med Educ 2009: 43: 1036-1043.

15. General Dental Council UK. Standards for Education - Standards and requirements for educators. London: General Dental Council, 2015 (revised edition). https://www.gdcuk.org/professionals/education

16. Steele JC, Clark HJ, Hong CH, Jurge S, Muthukrishnan A, Kerr AR, Wray D, Prescott-Clements L, Felix DH, Sollecito TP. World Workshop on Oral Medicine VI: an international validation study of clinical competencies for advanced training in oral medicine. Oral Surg Oral Med Oral Pathol Oral Radiol 2015: 120: 143-151.

17. Hein C, Schönwetter DJ, lacopino AM. Inclusion of oral-systemic health in predoctoral/undergraduate curricula of pharmacy, nursing, and medical schools around the world: a preliminary study. J Dent Educ 2011: 75: 1187-1199.

18. Harford J. Population ageing and dental care. Community Dent Oral Epidemiol 2009: 37: 97-103.

19. Kleinman ER, Harper PR, Gallagher JE. Trends in NHS primary dental care for older people in England: implications for the future. Gerodontology 2009: 26: 193-201.

20. Marcenes W, Kassebaum NJ, Bernabé E, et al. Global burden of oral conditions in 1990-2010: a systematic analysis. J Dent Res. 2013: 92: 592-597. 
21. Waldman HB, Rader R, Perlman SP. Health related issues for individuals with special health care needs. Dent Clin North Am 2009: 53: 183-193.

22. Commission of the European Communities. Green paper on the European workforce for health. COM 2008: 725. http://ec.europa.eu/health/ph systems/docs/workforce gp en.pdf

23. Montgomery-Cranny J, Edmondson M, Reid J, Eapen Simon S, Hegarty AM, Mighell AJ. Development of a Managed Clinical Network in Oral Medicine. Brit Dent J 2017: 223: 633-638.

24. Singh DG, Boudville N, Corderoy R, Ralston S, Tait CP. Impact on the dermatology educational experience of medical students with the introduction of online teaching support modules to help address the reduction in clinical teaching. Austral J Dermatol 2011: 52: 264-269.

25. van der Vleuten CPM and Newble DI. How can we test clinical reasoning? Lancet 1995: 345: 10321034.

26. Dawson LJ, Mason BG, Bissell V, Youngson C. Calling for a re-evaluation of the data required to credibly demonstrate a dental student is safe and ready to practice. Eur J Dent Educ 2017: 21: 130135.

27. General Medical Council. Medical Licencing Assessment. http://www.gmcuk.org/education/29000.asp 
Table 1. Competency Framework - Scope of Practice. Prior to registration as an independent practitioner, a student should be able to relate normal structure and function (taking account of age and physiological-related variations) to recognise and initiate management for: 


\begin{tabular}{|c|c|c|}
\hline Group & Outcome & Examples (that do not represent a complete list of all possibilities) \\
\hline \multirow{15}{*}{ 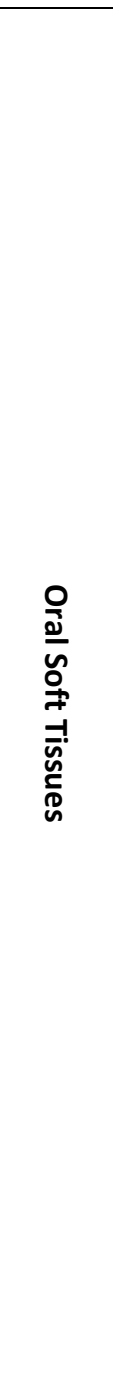 } & $\begin{array}{l}\text { Inflammatory/immune driven mucocutaneous diseases characterised by white, } \\
\text { red, atrophic, bullous and/or ulcerated lesions }\end{array}$ & $\begin{array}{l}\text { Lichen planus, lichenoid lesions, Graft versus Host Disease, mucous membrane } \\
\text { pemphigoid, pemphigus vulgaris, erythema multiforme, oral submucous } \\
\text { fibrosis. }\end{array}$ \\
\hline & Recurrent oral ulceration & $\begin{array}{l}\text { Recurrent aphthous stomatitis. } \\
\text { Recurrent oral ulceration associated with systemic illness such as Behçet's } \\
\text { disease, Crohn's disease and coeliac disease. } \\
\text { Recurrent oral ulceration associated with medication or other iatrogenic } \\
\text { events. }\end{array}$ \\
\hline & \multirow{3}{*}{ Infections (acute and/or persistent) } & Fungal infections: different forms of oral candidiasis including angular cheilitis. \\
\hline & & $\begin{array}{l}\text { Viral infections: Herpes Simplex Virus infections ( HSV), Human Papillomavirus } \\
\text { (HPV), systemic viral infections with oral manifestations. }\end{array}$ \\
\hline & & Bacterial infections: angular cheilitis, acute necrotising ulcerative gingivitis. \\
\hline & $\begin{array}{l}\text { Malignant and potentially malignant lesions }{ }^{1} \text { characterised by white, red and/or } \\
\text { ulcerated lesions }\end{array}$ & $\begin{array}{l}\text { Epithelial dysplasia. } \\
\text { Epithelial neoplasia (squamous cell carcinoma) or other malignancy including } \\
\text { metastases. }\end{array}$ \\
\hline & \multirow[t]{4}{*}{ Pigmented lesions } & $\begin{array}{l}\text { Melanin: macule, naevi, post-inflammatory, manifestations of systemic states, } \\
\text { malignant melanoma, drug-induced. }\end{array}$ \\
\hline & & Vascular lesions: haemangioma, Kaposi's sarcoma. \\
\hline & & $\begin{array}{l}\text { Exogenous pigments on the mucosal surface: pigmented foods and drinks, } \\
\text { tobacco, areca nut, or medication such as chlorhexidine. }\end{array}$ \\
\hline & & Exogenous pigments in the connective tissue: tattoos, drug-induced. \\
\hline & Traumatic lesions due to physical, chemical, thermal or ionizing radiation & Frictional keratosis, factitious injury, radiotherapy changes, recreational drugs. \\
\hline & \multirow[t]{2}{*}{ Conditions characterised by swelling } & Acute onset swelling: angioedema, including drug-induced. \\
\hline & & $\begin{array}{l}\text { Chronic swelling: reactive soft tissue overgrowths (including polyps and } \\
\text { epulides), neoplasms (including primary and secondary involvement of lymph } \\
\text { nodes), drug-induced overgrowths, orofacial granulomatosis, Crohn's disease. }\end{array}$ \\
\hline & \multirow[t]{2}{*}{ Developmental states } & Genodermatoses: white sponge naevus. \\
\hline & & Others: geographic tongue/benign migratory glossitis. \\
\hline
\end{tabular}

${ }^{1}$ Descriptive clinical terms such as 'leukoplakia' (white patch), 'erythroleukoplakia' (red/white patch) and 'erythroplakia' (red patch) are NOT indicative of a definitive tissue histopathological diagnosis such as 'dysplasia' or 'squamous cell carcinoma'. These descriptive clinical terms should be used with caution.

Oral Medicine for Undergraduate Dental Students - A Curriculum 
Table 1. Competency Framework - Scope of Practice. Continued.

\begin{tabular}{|c|c|c|}
\hline & Outcome & Examples (that do not represent a complete list of all possibilities). \\
\hline \multirow{6}{*}{ 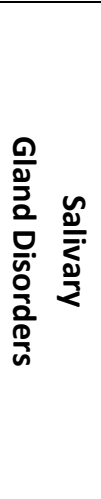 } & Conditions characterised by oral dryness & $\begin{array}{l}\text { Sjögren's Syndrome, poorly controlled diabetes mellitus, sarcoidosis, hepatitis } \\
\text { C, HIV, anxiety, iatrogenic (medication, radiotherapy or Graft versus Host } \\
\text { Disease). }\end{array}$ \\
\hline & Conditions characterised by excess saliva & Sialorrhoea and drooling. \\
\hline & \multirow[t]{2}{*}{ Conditions characterised by salivary gland swelling } & $\begin{array}{l}\text { Acute onset due to saliva outflow obstruction: sialocysts, salivary calculi or } \\
\text { ductal strictures. }\end{array}$ \\
\hline & & Chronic: neoplasia including lymphoma, sialosis. \\
\hline & \multirow[t]{2}{*}{ Infections (acute and/or persistent) } & $\begin{array}{l}\text { Viral infections: EBV-associated disease, hand foot and mouth disease, mumps, } \\
\text { HIV, hepatitis C. }\end{array}$ \\
\hline & & Bacterial infections: acute or chronic sialadenitis. \\
\hline \multirow{2}{*}{ 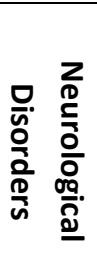 } & $\begin{array}{l}\text { Conditions characterised by episodic or persistent orofacial pain and/or } \\
\text { associated with abnormalities of sensation not explicitly arising from a tooth or } \\
\text { the supporting periodontium }\end{array}$ & $\begin{array}{l}\text { Trigeminal neuralgia, burning mouth syndrome, persistent idiopathic facial } \\
\text { pain, atypical odontalgia. }\end{array}$ \\
\hline & Conditions characterised by other nervous system dysfunction & $\begin{array}{l}\text { Cranial nerve abnormalities such as trigeminal nerve altered sensation, facial } \\
\text { nerve weakness. }\end{array}$ \\
\hline \multirow{2}{*}{ 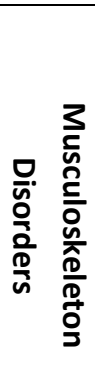 } & $\begin{array}{l}\text { Conditions characterised by altered quantity or quality of bone in the facial } \\
\text { skeleton }\end{array}$ & $\begin{array}{l}\text { Tori/exostoses, osteoporosis, Paget's disease of bone, acromegaly, iatrogenic } \\
\text { conditions including bisphosphonate-related osteonecrosis or } \\
\text { osteoradionecrosis. }\end{array}$ \\
\hline & $\begin{array}{l}\text { Conditions characterised by pain or other symptoms arising from the facial } \\
\text { skeleton and associated soft tissues including joints, muscles, connective tissues } \\
\text { and vasculature. }\end{array}$ & Temporomandibular joint disorders (articular and muscular), giant cell arteritis. \\
\hline
\end{tabular}


Table 2: Competency Framework - Priorities for practice. For conditions that fall within the scope of practice of Oral Medicine, a newly registered dentist should be able to make informed clinical decisions with consideration of:

\begin{tabular}{|c|c|c|}
\hline & Outcome & Examples (that do not represent a complete list of all possibilities). \\
\hline \multirow[t]{2}{*}{$\begin{array}{l}\text { Patient } \\
\text { Priorities }\end{array}$} & Patient concerns & $\begin{array}{l}\text { Some patient concerns are obvious (e.g. detrimental impact on day-to-day living of painful oral conditions). } \\
\text { There should be recognition that patients may not share all their concerns unless specifically asked (e.g. } \\
\text { concerns about serious diagnoses such as cancer, possible links to symptoms elsewhere in the body or the } \\
\text { relevance of information from sources such as the internet). } \\
\text { There should be recognition that patient views are shaped by culture and beliefs and that these may be } \\
\text { very different from those of the healthcare professional. }\end{array}$ \\
\hline & Patient expectations & $\begin{array}{l}\text { Explore patient expectations and make a judgement as to how these match available management } \\
\text { options. }\end{array}$ \\
\hline \multirow{3}{*}{ Diagnosis } & Working or definitive diagnosis & Assimilation of history, examination and investigations. \\
\hline & Involvement beyond the mouth & $\begin{array}{l}\text { Focal or non-focal problem? Is the problem limited to the oral cavity or does it also involve other parts of } \\
\text { the body? }\end{array}$ \\
\hline & The likelihood of a significant diagnosis & $\begin{array}{l}\text { Low stakes or high stakes diagnosis? In high stakes conditions diagnostic delay can result in significant } \\
\text { unnecessary patient morbidity. }\end{array}$ \\
\hline \multirow[t]{4}{*}{ Management } & $\begin{array}{l}\text { Aims of care (within matched } \\
\text { patient/clinician expectations) }\end{array}$ & $\begin{array}{l}\text { Cure. } \\
\text { Control and risk reduction. } \\
\text { Cancer surveillance. }\end{array}$ \\
\hline & Range of options & $\begin{array}{l}\text { Reliable information (including appropriate patient information leaflets or internet sites). } \\
\text { Support (including by the practitioner and via patient support groups). } \\
\text { Risk reduction measures associated with tobacco, alcohol, areca nut, illicit drugs or other recreational } \\
\text { habits and sunlight. } \\
\text { Oral hygiene instruction and therapy (including choice of toothpaste). } \\
\text { Topical medication (including over-the-counter preparations). } \\
\text { Systemic medication (including over-the-counter preparations). } \\
\text { Other interventions (including bite guards). } \\
\text { Referral or liaison with others (with appropriate explanation to patient). }\end{array}$ \\
\hline & Risk and Benefit & $\begin{array}{l}\text { Do the potential advantages (benefit) of any therapeutic intervention outweigh potential disadvantages } \\
\text { (risks)? } \\
\text { Appropriate intervention use and information-sharing with regards to adverse events. }\end{array}$ \\
\hline & Temporal & $\begin{array}{l}\text { What care has been received to date for this problem (including diagnostic investigations and treatments) } \\
\text { with consideration of care provided by other healthcare workers and care that has been self-directed (such } \\
\text { as over-the-counter treatments). }\end{array}$ \\
\hline
\end{tabular}

Oral Medicine for Undergraduate Dental Students - A Curriculum 


\begin{tabular}{|l|l|l|}
\hline & & $\begin{array}{l}\text { Natural history of the condition. } \\
\text { Patient priorities changing over time. }\end{array}$ \\
\cline { 2 - 3 } & Concordance & The process of successful management based on partnership. \\
\cline { 2 - 3 } & Review and Re-evaluation & Review and re-evaluation at timely intervals to ensure care remains appropriate. \\
\hline
\end{tabular}

